\title{
ANÁLISE DA EDUCAÇÃO AMBIENTAL EM UMA ESCOLA ESTADUAL NO MUNICÍPIO DE ARARIPINA (PE)
}

\author{
Francisca Aline de Oliveira Torres ${ }^{1}$ \\ Danilo Diego de Souza ${ }^{2}$
}

Resumo: O objetivo deste trabalho foi analisar os conceitos e fundamentos da Educação Ambiental (EA) de professores e alunos de uma escola estadual de Araripina-PE. Nesse estudo, constatou-se que os docentes entrevistados demonstraram ser sensíveis a causa ambiental e orientar os alunos em relação aos cuidados com o ambiente escolar é um passo inicial para formar um cidadão consciente. Para a maioria dos alunos entrevistados, o meio ambiente é o seu meio de sobrevivência, pois sem a natureza não tem vida, enquanto para melhorar e/ou conservar o meio em que vivem, a maioria entende que, é necessário reduzir a poluição. A EA deve estar presente nas escolas, pois é uma ferramenta transformadora que contribuiu para formar cidadãos críticos.

Palavras-chave: Educação; Meio Ambiente; Escola.

Abstract: The objective of this work was to analyze the concepts and foundations of Environmental Education (EE) of teachers and students of a state school in Araripina (PE, Brazil). In this study, it was found that the teachers interviewed demonstrated to be sensitive to the environmental cause and guiding students in relation to the care for the school environment is an initial step to form a conscious citizen. For most of the students interviewed, the environment is their means of survival, because without nature there is no life, while to improve and/or conserve the environment in which they live, most understand that it is necessary to reduce pollution. EE must be present in schools, as it is a transformative tool that has contributed to forming critical citizens.

Keywords: Education; Environment; School.

${ }^{1}$ Universidade Lusófona de Humanidades e Tecnologias, Portugal. E-mail: franciscaalinetorres@hotmail.com.

2 Agência Municipal de Meio Ambiente de Ouricuri (PE). E-mail: danilodiegos@hotmail.com. 


\section{Introdução}

Nos últimos tempos, os ambientalistas têm se preocupado e intensificado mais as discussões com a problemática da preservação e conservação do Planeta. Porém, o pensamento mais acentuado ligado à temática ambiental já vem de longas datas, sem falar que tem acontecido grandes e renomados eventos e sucessivos documentos que foram acordados a nível internacional dessa natureza para minimizar os impactos ambientais. Dessa forma, os desafios socioambientais se tornaram mais evidentes e é necessário refletir sobre as práticas sociais e ambientais, em um contexto marcado pela degradação dos recursos naturais.

Segundo Brasil (2012, p.2), a Educação Ambiental (EA) é uma atividade intencional da prática social, a qual deve imprimir ao desenvolvimento dos indivíduos um caráter social em sua relação com os recursos naturais e com o ser humano, objetivando fortalecer essa atividade humana com o intuito de torná-la plena de ética ambiental e de prática social.

A EA é um fator preponderante para educar o indivíduo a cuidar dos recursos naturais com conhecimento e responsabilidade (FERREIRA, 2011). No ambiente escolar, a EA deverá estar presente em todos os níveis de ensino, assim como uma prática educativa integrada, incluindo todos os docentes, que deverão incluir a temática ambiental nos diversos assuntos abordados em sala de aula (ALENCAR et al., 2016).

A Educação Ambiental desperta a conscientização ecológica do educando e a escola deve promover práticas pedagógicas para formar cidadãos conscientes. $O$ aspecto mais importante está na missão que a escola tem, de planejar e tratar esse tema e de como o educando mantém essa relação com a natureza e com a sociedade. Assim, de acordo com Lima (2004), a escola pode construir um espaço para o desenvolvimento da Educação Ambiental, objetivando formar cidadãos conscientes, capazes de enfrentar os desafios da realidade socioambiental.

O objetivo deste trabalho foi analisar os conceitos e fundamentos da Educação Ambiental de professores e alunos de uma escola da rede estadual localizada no município de Araripina-PE, e suas relações, abordando o modo de interação dos professores e alunos com a natureza, por meio de suas relações sociais, visando assim uma conscientização e/ou sensibilização ambiental que contemple as questões da vida cotidiana das pessoas como cidadãos e discuta algumas visões polêmicas sobre essa temática.

\section{Metodologia}

A escola campo da pesquisa fica localizada no Município de Araripina$\mathrm{PE}$, que funciona nos turnos manhã, tarde e noite. O estudo foi desenvolvido em 13 turmas, divididas entre Ensino Fundamental II e Ensino Médio. A pesquisa foi realizada com 20 professores (Ciências, Biologia, Geografia, Matemática, Artes, História e Inglês) e 200 alunos (Quadro 1). 
Quadro 1: Descrição da pesquisa.

\begin{tabular}{|l|l|}
\hline Descrição & Quantidade \\
\hline Turmas & 13 \\
\hline Professores & 20 \\
\hline Alunos & 200 \\
\hline
\end{tabular}

Fonte: Autores (2018).

Para a realização deste estudo, foram coletadas informações por meio de um questionário com professores e alunos da escola, no qual introduziu-se possibilidades e variações de habilidades para 0 esclarecimento das indagações realizadas. A partir dessas informações, formaliza-se o principal instrumento de coleta de dados para o trabalho de campo.

Diante disso, o presente questionário tratou-se de abordar os entrevistados sobre as seguintes questões: A importância da Educação Ambiental na opinião dos professores; os temas da Educação Ambiental que o professor deve tratar em sala de aula; se os professores orientam os alunos em relação aos cuidados com a escola; o que os alunos entendem sobre meio ambiente; o que são problemas ambientais na visão dos alunos e o que os alunos tem feito para melhorar e/ou conservar o meio em que vivem.

Após a conclusão da coleta de dados, foi realizado o processamento e análise dos dados utilizando o programa Microsoft Excel. Em seguida, os dados coletados foram apresentados em forma de gráficos.

\section{Resultados e Discussão}

Perguntou-se aos professores, o que eles podiam fazer para ajudar a sensibilizar os alunos em relação a temática ambiental para que a atuação dos alunos influencie positivamente na relação com o meio ambiente. Desses, $40 \%$ responderam que o mais importante é sensibilizar os docentes em relação aos possíveis problemas e soluções sofridos pelo Planeta, assim, buscar a melhoria e conscientização/sensibilização do alunado. Os outros $60 \%$ indagaram em relação a estimular a participação dos pais, alunos, funcionários e professores, resgatando e fortalecendo a responsabilidade pelas questões ambientais (Figura 1, próxima página).

De acordo com o estudo desenvolvido por Gonzaga (2008, p.113), para a maior parte dos professores entrevistados, a importância da Educação Ambiental reside principalmente no caráter conscientizador e, por sua vez, se operacionaliza na capacidade de conscientizar os indivíduos sobre a existência da crise ambiental, na capacidade de conscientizá-los para preservar e que a soma de suas atitudes são importantes para enfrentar a crise e alcançar o equilíbrio. 


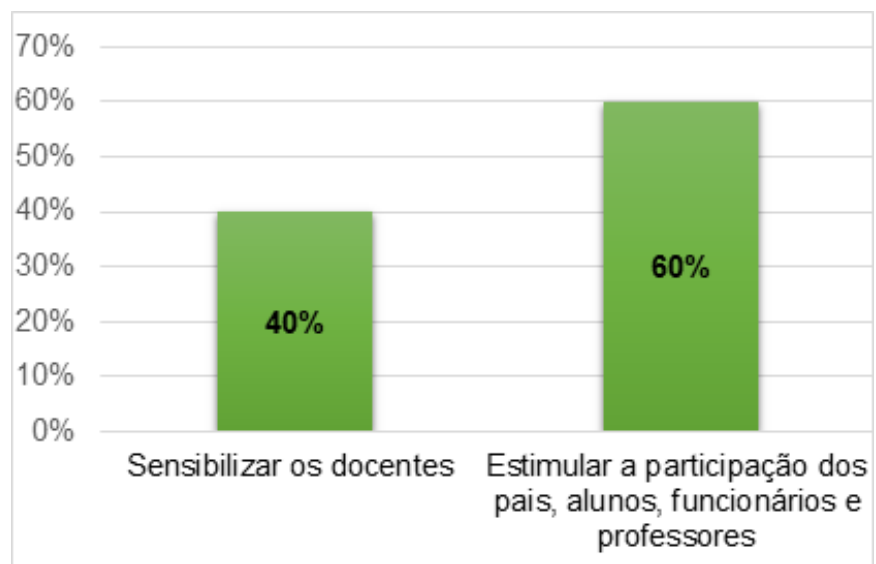

Figura 1: Opinião dos professores sobre como tentar ajudar a sensibilizar e/ou conscientizar os alunos sobre a temática ambiental. Fonte: Autores (2018).

Dessa forma, a inclusão da Educação Ambiental, numa perspectiva de educação permanente, nas práticas pedagógicas dos professores é essencial para ajudar a sensibilizar e/ou conscientizar os alunos sobre a temática ambiental, para que estes possam refletir sobre suas práticas sociais e compreender a importância de uma boa conduta em relação ao meio ambiente.

Promover a capacitação dos professores para a Educação Ambiental é necessário para preparar o aluno para agir corretamente diante da problemática ambiental. Segundo Said e Santos (2017, p.2), a falta de capacitação continuada traz consequências ao ensino da Educação Ambiental na escola, pois o discente não se encontra preparado para tratar de um conteúdo complexo e ao mesmo tempo contemporâneo, o que torna o ensino deficiente.

Utilizando essa mesma linha, perguntou-se aos professores quais os temas da Educação Ambiental que são mais abordados. Dos educadores entrevistados, $50 \%$ responderam que deve ser tratada a questão do desmatamento, $30 \%$ indagaram a questão dos resíduos sólidos, como reciclagem e reutilização, e outros $20 \%$ indagaram a questão da água como deve ser usada (Figura 2).

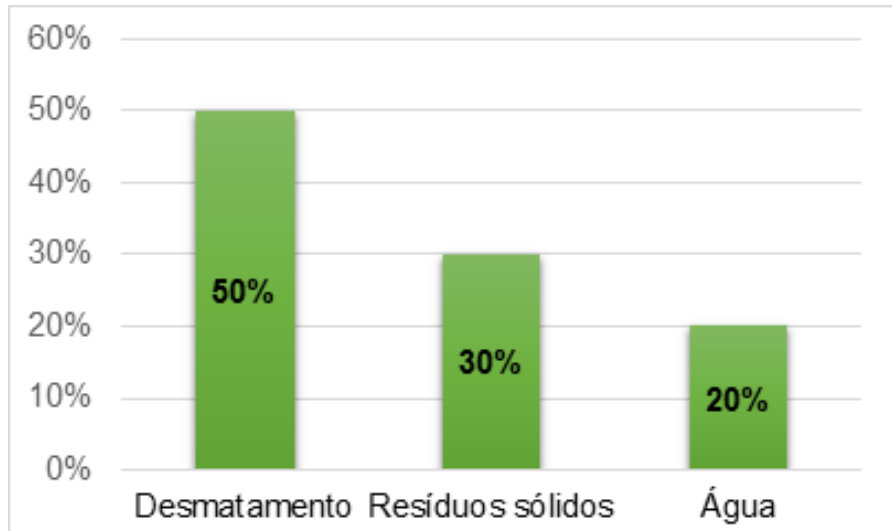

Figura 2: Temas da Educação Ambiental que são mais abordados pelos professores. Fonte: Autores (2018). 
Na pesquisa desenvolvida por Silva (2016, p. 10), em entrevista com a gestora da escola, esta salientou que a escola deve sempre tratar de temas como o uso da água sem desperdício, da coleta seletiva, dos cuidados com o solo, vegetação e com os recursos naturais. Já na pesquisa desenvolvida por Fath $(2011$, p. 40), este cita os seguintes temas que os professores devem tratar: desenvolvimento sustentável, reciclagem, compostagem, poluição da água e do solo, qualidade ambiental, preservação do meio ambiente, artes, cultura e cidadania.

Para concluir as perguntas questionadas aos professores da escola, perguntou-se se eles orientam os alunos em relação aos cuidados com a escola como: papel no chão, cuidados com as árvores e economia de água. $90 \%$ responderam que sim, pois a escola tem uma disciplina rigorosa e não aceita que os alunos sujem a escola e $10 \%$ responderam que às vezes chama a atenção dos alunos com conversa informal em relação a não sujar a escola (Figura 3).

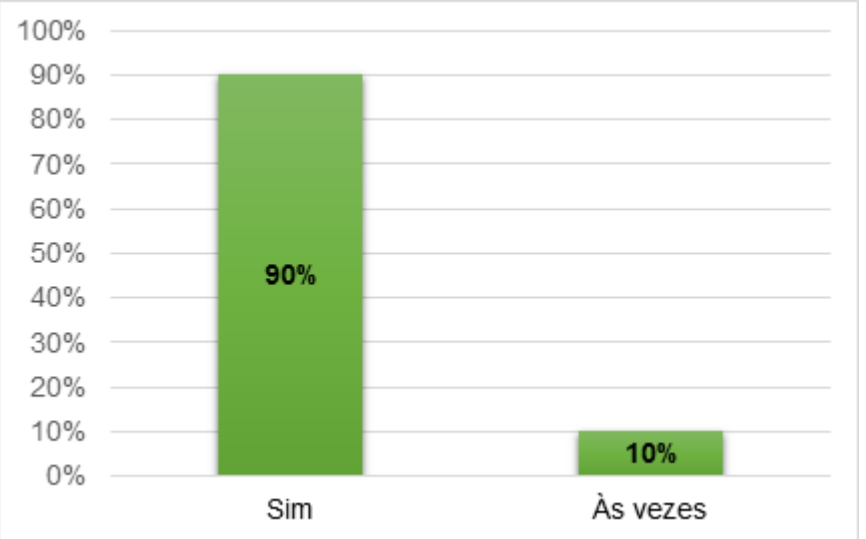

Figura 3: Os professores orientam os alunos em relação aos cuidados com a escola.

Fonte: Autores (2018).

Galvão (2002, p.68) cita, em um depoimento de uma professora, que a docente procura cuidar da escola, solicitando que os alunos recolham os papéis espalhados no ambiente escolar. A docente sempre dá exemplos de como ter cuidado com a escola, explicando também como proceder os cuidados com as plantas, como por exemplo, regar as plantas dos jardins da escola.

De acordo com Lima, Aranda e Lima (2012, p.63), gerir democraticamente uma escola é muito mais do que fiscalizá-la, contribuir financeiramente, cuidar de alunos no intervalo, ajudar a varrer, pintar, ajudar na feitoria da merenda, cuidar da escola é buscar e materializar o sentido de consciência coletiva.

Sobre a entrevista dos alunos, indagou-se sobre o meio ambiente. Assim, $60 \%$ dos alunos falaram que o meio ambiente é meio de sobrevivência, pois sem a natureza não tem vida, enquanto $40 \%$ falaram em relação à preservação do mesmo, pois o meio ambiente é tudo que existe no mundo (Figura 4). 


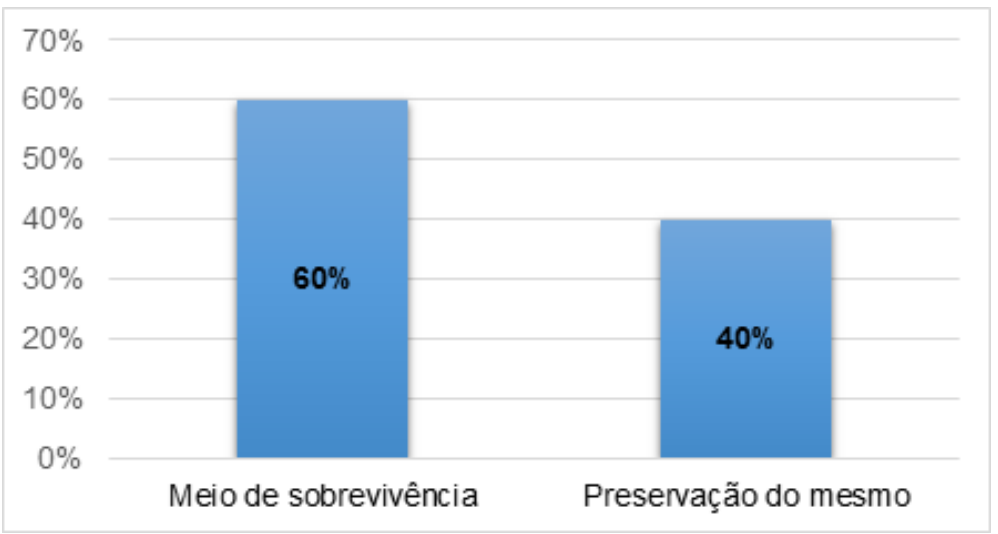

Figura 4: O que os alunos entendem sobre meio ambiente. Fonte: Autores (2018).

Em estudo realizado por Souza e Severiano (2018, p.170) com estudantes do ensino fundamental, no qual foi aplicado um formulário onde se buscava compreender o que os alunos entendem sobre meio ambiente. Sobre isso, $28 \%$ responderam que sabiam qual o significado da expressão meio ambiente, enquanto $72 \%$ responderam não saber o que significava.

Diante disso, é necessário criar uma consciência coletiva no alunado sobre o significado de meio ambiente para que, a partir dessa fundamentação teórica, possamos ter uma visão melhor do nosso meio e, desta forma, contribuir melhor com o nosso meio ambiente, seja ele natural ou modificado.

Perguntou-se aos alunos o que são problemas ambientais. $70 \%$ responderam que é tudo que prejudica o meio ambiente e $30 \%$ falaram em relação à poluição causada pelo homem, como as fábricas de gesso e o desmatamento (Figura 5).

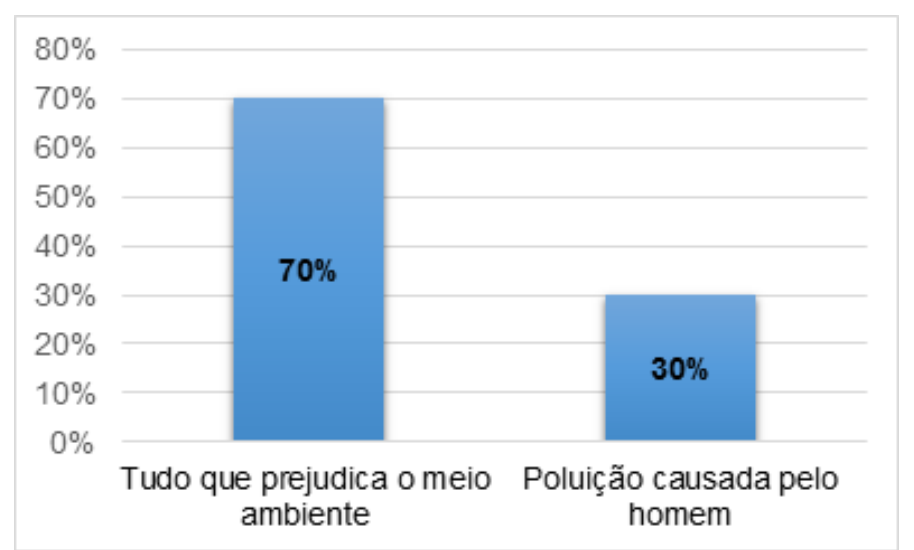

Figura 5: O que são problemas ambientais na visão dos alunos. Fonte: Autores (2018).

Em pesquisa realizada com estudantes do ensino fundamental por Loiola (2016, p. 63), perguntou-se aos alunos sobre os problemas ambientais na visão deles. O autor tinha como previsão de resposta que eles 
relacionassem a fatores de não poluir, não desmatar, não queimar ou até mesmo não desperdiçar. Realmente, $70 \%$ das respostas condiziam ao que os autores esperavam, os $30 \%$ restantes se deram por motivos de os alunos responderem "destruição do mundo", "não cortar árvore, sem elas não podemos respirar", relação que os alunos fazem sobre a importância do ar para nossa sobrevivência.

De acordo com a figura abaixo, indagou-se aos alunos o que eles tem feito para melhorar e/ou conservar o meio em que vivem. $60 \%$ responderam que poluindo menos vai solucionar os problemas, $30 \%$ disseram que precisar ser mais conscientes em relação ao meio ambiente e $10 \%$ falaram em relação aos resíduos, como saber reaproveitá-los (Figura 6).

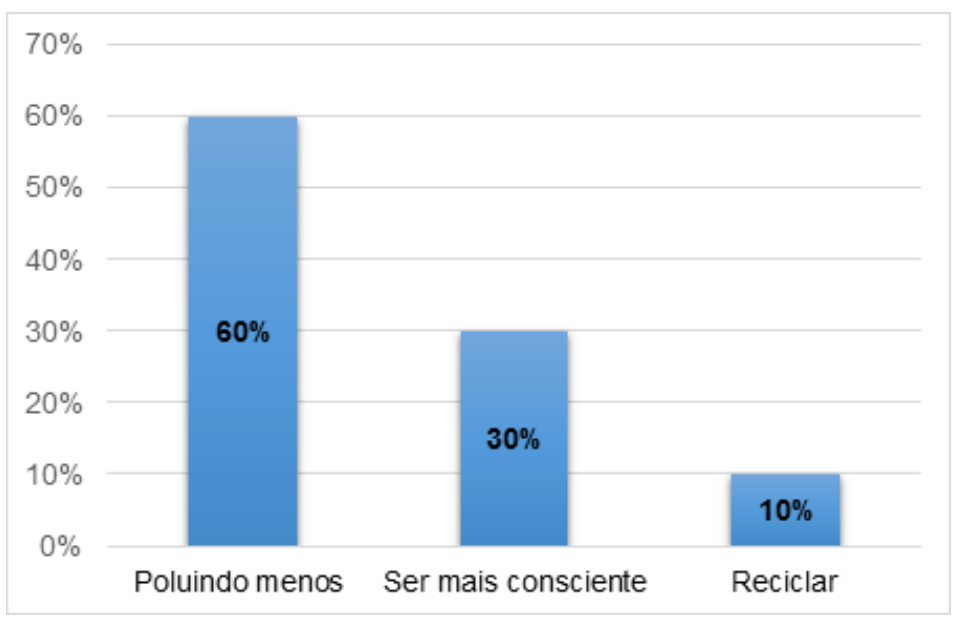

Figura 6: $O$ que os alunos tem feito para melhorar e/ou conservar o meio em que vivem.

Fonte: Autores (2018).

Segundo Nascimento, Machado e Dantas (2013, p.114), ao questionar os alunos do ensino fundamental sobre o que faziam para melhorar o meio ambiente, $71,9 \%$ assumiram fazer o gerenciamento dos resíduos para contribuir com o meio ambiente. Sobre questões relacionadas à vegetação, apenas $31,3 \%$ afirmavam ter preocupação com o desmatamento e realizar reflorestamento.

A escola é um ambiente de aprendizagem e é essencial abrir espaço para o estudante atuar como sujeito do processo, aprendendo a identificar os problemas ambientais e sua responsabilidade ambiental diante dessa problemática. Com ações concretas, o professor, como mediador e conscientizador/sensibilizador no seu campo de ensino, deve navegar por outros caminhos, trabalhar diversas estratégias dinamizar e trabalhar com os grandes subsídios que norteiam o processo de ensino. Pode trabalhar 0 educando crítico para agir compreender e confrontar com os problemas inserindo esse conhecimento para a vida toda como prática educativa e não só com projetos ou eventos de vez em quando, mas como prática educativa o 
antes, o durante e o depois de todo o processo de ensino, indispensável para nossa sobrevivência.

Vale salientar que a escola realizou projetos de conscientização com a comunidade escolar em relação a demonstrar a responsabilidade do ser humano com a preservação e conservação do meio ambiente, dando um destino adequado aos resíduos produzidos, tanto na escola quanto na comunidade em que vivem. Os projetos de EA podem ser excelentes recursos para o processo de ensino-aprendizagem no contexto escolar, mas eles precisam ser realizados de maneira que conecte todas as áreas da escola e abranjam um tempo considerável para que os seus resultados possam ser avaliados.

Esse processo de sensibilização da comunidade escolar pode fomentar iniciativas que transcendam o ambiente escolar, atingindo tanto o bairro no qual a escola está inserida, como comunidades mais afastadas nas quais residam alunos, professores e funcionários, com potenciais multiplicadores de informações e atividades relacionadas à Educação Ambiental implementada na escola (SOUZA; SANTOS, 2012).

A orientação sobre Educação Ambiental é fundamental na resolução dos problemas de impactos ambientais, pois por meio dos conhecimentos adquiridos, o aluno torna-se mais consciente. A sustentabilidade é o novo caminho para amenizar os problemas e salvar o futuro. Esse entendimento se dá dentro da sala de aula com base nos currículos e planejamentos bem alinhados, o que em algumas práticas pedagógicas tem melhorado.

\section{Considerações Finais}

Nessa pesquisa, constatamos que os docentes entrevistados demonstraram ser sensíveis à causa ambiental e orientar os alunos em relação aos cuidados com o ambiente escolar é um passo inicial para formar um cidadão consciente. Podemos viver em harmonia com a natureza, rever os conceitos ambientais, produzir menos resíduos e gerenciá-los corretamente, adquirir boas práticas de manejo e conservação da natureza e deixar de ser agente de degradação para ser um agente de mudança, objetivando viver em sintonia com a natureza. Dessa forma, envolver os alunos em ações educativas sobre o meio ambiente é essencial para tentar mudar o comportamento destrutivo da humanidade, uma vez que a Educação Ambiental pode resgatar novos agentes ambientais do futuro.

Para a maioria dos alunos, o meio ambiente é o seu meio de sobrevivência, pois sem a natureza não tem vida, enquanto para melhorar e/ou conservar o meio em que vivem, a maioria entende que, poluindo menos, solucionará os problemas ambientais. Diante disso, a Educação Ambiental deve estar presente nas escolas, pois é uma ferramenta transformadora que contribui para formar cidadãos críticos em prol de uma sociedade mais justa e ecológica. 


\section{Referências}

ALENCAR, L. D.; ALENCAR, L. D.; BARBOSA, M. F. N.; BARBOSA, E. M. Educação Ambiental no ensino público: percepção dos professores de uma escola de Campina Grande-PB. Revista Espacios, Caracas, v. 37, n. 18, 2016.

BRASIL. Resolução no 2, de 15 de junho de 2012. Estabelece as Diretrizes Curriculares Nacionais para a Educação Ambiental. Diário Oficial da União: seção 1, Brasília, DF, 18 jun. 2012.7 p.

FATH, E.C. Diagnóstico e atividades relacionadas à Educação Ambiental em escolas públicas de São Paulo-SP e Blumenau-SC. Dissertação (Mestrado em Ensino de Ciências), Universidade de São Paulo, Faculdade de Educação, Instituto de Física, Instituto de Química e Instituto de Biociências. São Paulo, 2011, 121 f.

FERREIRA, A. C. S. Contabilidade ambiental: uma informação para o desenvolvimento sustentável. 3. ed. São Paulo: Atlas, 2011. 152 p.

GALVÃO, Z. Educação física escolar: a prática do bom professor. Revista Mackenzie de Educação Física e Esporte, São Paulo, v. 1, n. 1, p. 65-72, 2002.

GONZAGA, M. J. B. Educação Ambiental: um estudo de experiências nas escolas municipais de Natal. Dissertação (Mestrado em Ciências Sociais) - Universidade Federal do Rio Grande de Norte, Centro de Ciências Sociais, Natal, 2008, $160 \mathrm{f}$.

LOIOLA, J. L. Atividades contextualizadas de Matemática: a formação do sujeito ecológico em alunos do 5o ano do ensino fundamental. 2016. $188 \mathrm{f}$. Dissertação (Mestrado em Educação para Ciências e Matemática) - Instituto Federal de Educação, Ciência e Tecnologia de Goiás, Programa de Pós-Graduação em Educação para Ciências e Matemática, Campus Jataí, 2016.

LIMA, W. Aprendizagem e classificação social: um desafio aos conceitos. Fórum Crítico da Educação, Rio de Janeiro, v. 3, n. 1, p. 29-55, 2004.

LIMA, P. G.; ARANDA, M. A. M.; LIMA, A. B. Políticas educacionais, participação e gestão democrática da escola na contemporaneidade brasileira. Ensaio Pesquisa em Educação em Ciências, Belo Horizonte, v. 14, n. 1, p. 51-64, 2012.

NASCIMENTO, G. M.; MACHADO, D. D.; DANTAS, M. C. Percepção de alunos da zona rural de Crateús-CE sobre o tema meio ambiente. Revista Ouricuri, Paulo Afonso, v. 3, n. 2, p. 106-127, 2013.

SAID, F.; SANTOS, S. C. A importância da Educação Ambiental à distância na capacitação de professores de Geografia. Projeção e Docência, Taguatinga, v. 8, n. 1, p. 1-8, 2017.

SILVA, S. G. Educação Ambiental escolar: estudando teorias e visualizando iniciativas realizadas no colégio módulo em Juazeiro do Norte-CE. Geosaberes, Fortaleza, v. 6, n. 3, p. 16-26, 2016.

SOUZA, R. M.; SANTOS, M. M. Análise da prática pedagógica em Educação Ambiental no contexto de escola rural em Itaporanga D'Ájuda-SE. Revista Vitas, Rio de Janeiro, n. 2, p. 1-17, 2012.

SOUZA, R. N. S; SEVERIANO, J. S. Construção do conhecimento sobre as aves da Caatinga através de atividades lúdicas no processo de ensino e aprendizagem. Revista Principia, João Pessoa, n. 44, p. 163-175, 2018. 